\title{
Infecciones micóticas del tracto urogenitalmasculino, importantes aunque poco frecuentes: revisión sistemática
}

\author{
Fungal infections of male genitourinary tract, \\ important though infrequent: a systematic review
}

\author{
Elizabeth X. Castrillón-Duque Biotec ${ }^{1}$, \\ Walter D. Cardona-Maya $P h D^{2}$
}

Introducción: las infecciones del tracto urogenital son una de las causas más frecuentes durante las consultas por infertilidad masculina. Comúnmente se evalúan aquellas causadas por bacterias y virus, mientras que las producidas por hongos han sido subvaloradas; sin embargo, en las últimas décadas su frecuencia ha aumentado. Objetivo: describir algunas micosis del tracto urogenital masculino y su posible efecto sobre la fertilidad. Materiales y métodos: se realizó una revisión sistemática de la literatura publicada sobre las micosis del tracto urogenital masculino y la fertilidad en las bases de datos PubMed, ScienceDirect, SciELO, Redalyc, Springer y Google Académico. Resultados: se encontraron un total de 3.426 publicaciones que hablaban sobre el tema. Entre la información revisada se comprobó que el $90 \%$ de las micosis reportadas en el tracto urogenital masculino son ocasionadas por Candida spp., Aspergillus spp., Cryptococcus spp. y Coccidioides spp., microorganismos que podrían ser los causantes de uretritis, balanopostitis, úlceras, pseudotumores, orquitis y prostatitis; además de afectar negativamente la calidad espermática, lo que causa alteraciones en la fecundación. Conclusiones: las infecciones fúngicas del tracto urogenital pueden desatar infertilidad, que si se tratan correctamente disminuirán la diseminación, morbilidad y mortalidad a causa de estos microrganismos.

\footnotetext{
${ }^{1}$ Estudiante de Biotecnología, Colegio Mayor de Antioquia. Estudiante, Grupo Reproducción, Departamento de Microbiología y Parasitología, Facultad de Medicina, Universidad de Antioquia. Medellín, Colombia. ${ }^{2}$ Bacteriólogo, MSc en Ciencias Básicas Biomédicas, PhD en Biología. Grupo Reproducción, Departamento de Microbiología y Parasitología, Facultad de Medicina, Universidad de Antioquia. Medellín, Colombia. Correspondencia: Carrera 53 \# 61-30. Sede de Investigación Universitaria (SIU), Laboratorio 534. Teléfono: 5742196476 - 2196477. Correo electrónico: wdario.cardona@udea.edu.co
}

Conflicto de intereses: los autores declaran que no tiene conflicto de intereses.

Medicina \& Laboratorio 2017; 23: 527-538

Módulo 27 (Salud Sexual y Reproductiva), número 6. Editora Médica Colombiana S.A. $2017^{\circ}$

Recibido el 18 de noviembre de 2016; aceptado el 12 de diciembre de 2016 
Palabras clave: espermatozoides, semen, fertilidad, hongos, micosis, Candida, Aspergillus, Cryptococcus, Coccidioides, Malassezia, Blastomyces.

Introduction: Urogenital tract infections are one of the most frequent causes during male infertility consults. Infections caused by bacteria and virus are commonly evaluated, but those caused by fungi are usually ignored. However, in the last decades urogenital tract fungi infections have increased. Objective: analyze the effect of several mycoses in the urogenital tract and male fertility. Materials and methods: It was explored about mycoses and male fertility in databases as PubMed, ScienceDirect, SciELO, Redalyc, Springer, and Google scholar. Results: We found a total of 3,426 manuscripts about mycoses and male fertility. Ninety percent of reported mycoses in the male reproductive tract are caused by Candida spp., Aspergillus spp., Cryptococcus spp., and Coccidioides spp., generating urethritis, balanoposthitis, ulcers, pseudotumors, orchitis, and prostatitis. Furthermore negatively affecting seminal quality. Conclusion: Fungal infections of urogenital system could cause male infertility, if that are properly treated, would reduce dissemination, morbidity and mortality, because this microorganisms.

Key words: Spermatozoa, semen, fertility, fungi, mycoses, Candida, Aspergillus, Cryptococcus, Coccidioides, Malassezia, Blastomyces.

Castrillón-Duque EX, Cardona-Maya WD. Infecciones micóticas del tracto urogenital masculino, importantes aunque poco frecuentes: revisión sistemática. Medicina \& Laboratorio 2017; 23: 527-538.

$\mathrm{L}$ a infertilidad es un problema de salud mundial que afecta a una de cada seis pas en edad reproductiva [1] y, contrario a lo que se piensa comúnmente a causa de la directa relación de la mujer con el embarazo, el factor masculino es el responsable de al menos el $50 \%$ de los casos [2,3]. Las alteraciones de la fertilidad masculina son originadas por una variedad de condiciones clínicas y enfermedades que afectan tanto a los órganos internos como a los externos, entre las que se incluyen las infecciones, las cuales, dependiendo del sitio anatómico en el que se presentan (uretra, próstata y uréteres) $[1,2,4,5]$ pueden generar lesiones genitales, prostatitis, uretritis, epididimitis y alteraciones en la calidad del semen. Este tipo de infecciones son producidas por bacterias, virus, protozoos y hongos, y se estima que entre el $8 \%$ y el $35 \%$ de las consultas por infertilidad son por esta causa [6-9].

La fertilidad masculina está directamente relacionada con la calidad del semen [1016], el cual es una combinación de los espermatozoides (aproximadamente el 10\%) y las secreciones de la próstata, las vesículas seminales y las glándulas bulbouretrales que se mezclan durante la eyaculación [9].

En el semen se ha identificado la presencia de bacterias como Enterococcus faecalis, Escherichia coli, Morganella morganii, Klebsiella pneumoniae, Staphylococcus 
spp., mediante espermocultivos [17] así como Chlamydia trachomatis, Neisseria gonorrhoeae y Ureaplasma urealyticum por reacción en cadena de la polimerasa (PCR) $[18,19]$; incluso, se ha reportado una serie de efectos deletéreos ejercidos por la presencia de las bacterias o los factores solubles que son producto de su metabolismo en el semen sobre la función espermática, lo que desencadena la infertilidad asociada a infecciones del tracto reproductivo masculino [17-21].

Algunas de las bacterias mencionadas anteriormente han sido reportadas como agentes etiológicos de infecciones de transmisión sexual (ITS). Cada día más de 1.000.000 de personas contraen una infección de este tipo, incluso se estima que cada año unas 357.000.000 personas contraen alguna de las infecciones de transmisión sexual de origen bacteriano, incluyendo la clamidiasis (aproximadamente 131.000 .000 ) y la gonorrea (alrededor de 78.000.000) [18,22].

De otro lado, se estima que el contagio mundial con virus de transmisión sexual es de 800.000.000 de personas por año, cifra que continúa en aumento. Algunos de los virus que más aportan a estas estadísticas son: herpesvirus humano, virus del papiloma humano, virus de la hepatitis $\mathrm{B}$ y $\mathrm{C}$, citomegalovirus y virus de la inmunodeficiencia humana (VIH) $[8,22]$. Particularmente, el VIH infecta principalmente a las células del sistema inmune, aunque se ha demostrado que se une e infecta a los espermatozoides humanos a través del receptor de manosa [8,23-26] y del heparán sulfato [27], lo que convierte al espermatozoide en un vehículo para el virus, ya sea hacia el tracto reproductivo femenino o hacia el oocito, lo que explicaría la transmisión vertical del virus del padre al hijo $[28,29]$. Otros virus han sido encontrados y descritos en el semen como el virus del ébola [30] y el virus Zika [31], por lo que pueden ser transmitidos por contacto sexual.

Por otra parte, las infecciones ocasionadas por bacterias y virus propician las condiciones óptimas para desarrollar infecciones por hongos, las cuales en la mayoría de los casos son asintomáticas, aunque se ha reportado que pueden generar lesiones, úlceras genitales, hinchazón inguinal, inflamación escrotal, dolor abdominal bajo y verrugas, además de afectar negativamente la calidad seminal [6,7,32-35]. A la fecha, se reconocen más de 400 especies de hongos causantes de micosis, las cuales representan entre el $3 \%$ y el $4 \%$ del total de especies fúngicas [36].

En las últimas décadas se ha observado un incremento de las infecciones micóticas, lo que ha significado la aparición de nuevas formas clínicas de micosis y de algunos de estos microorganismos en localizaciones no habituales como la próstata, el epidídimo y los riñones, entre otras $[33,35,37,38]$. El $90 \%$ de las micosis reportadas son ocasionadas por Candida spp., Aspergillus spp., Cryptococcus spp. y Coccidioides spp.; responsables en el tracto reproductivo masculino de algunos casos de uretritis, balanopostitis y prostatitis $[34,35,39]$. A su vez, se ha demostrado que el contacto de estos hongos con el semen, en el tracto reproductivo masculino o femenino, afecta la movilidad, la viabilidad y las funciones mitocon- 
driales de los espermatozoides $[32,40,41]$, por lo que se infiere que tienen una relación directa con la alteración del potencial fértil masculino.

El objetivo de esta revisión sistemática es recopilar y describir la literatura relacionada con las micosis del tracto urogenital masculino y su posible efecto sobre la fertilidad, específicamente sobre la calidad seminal.

\section{Materiales y métodos}

Se realizó una revisión sistemática de la literatura publicada sobre las micosis del tracto urogenital masculino y su relación con la fertilidad, empleando los términos «espermatozoide», «semen», «fertilidad», «hongos», «micosis», «Candida spp.», «Cryptococcus spp.», «Coccidioides spp.», «Aspergillus spp.», «Blastomyces spp.» y «Malassezia spp.», al igual que sus equivalentes en inglés en las bases de datos PubMed, ScienceDirect, SciELO, Redalyc, Springer y Google Académico. Se incluyeron el total de artículos publicados: artículos originales, reportes de casos clínicos, revisiones de tema y cartas al editor. Para la búsqueda no se abarcaron los límites cronológicos; de forma adicional se revisó la bibliografía reportada en cada artículo con el propósito de ampliar los resultados. De la totalidad de artículos revisados se eligieron los que presentaban la información más relevante según el criterio de los autores.

\section{Resultados}

La búsqueda mediante los términos seleccionados arrojó un total de 3.426 publicaciones, 1.285 en PubMed, 390 en ScienceDirect, 21 en SciELO, 15 en Redalyc, 155 en Springer y 1.560 en Google Académico. Se descartaron 3.392 que no se relacionaban con las micosis del tracto urogenital masculino ni con la fertilidad masculina y se seleccionaron 105 publicaciones, de las cuales 34 fueron utilizadas para la redacción de este manuscrito (véase figura 1 y tabla 1 ).

\section{Infecciones del tracto urinario masculino}

Las infecciones del tracto urinario en hombres son comunes y comprometen de igual forma al tracto reproductivo debido a que comparten varias porciones anatómicas [21]. Comúnmente se evalúan las infecciones causadas por bacterias y virus, mientras que las causadas por hongos suelen ser subvaloradas $[40,42,44,45]$.

Los hongos causantes de enfermedad en el humano se dividen en dos grupos: los patógenos primarios o verdaderos, es decir, aquellos que causan infección en un hospedero con función inmune normal, como Coccidioides spp. y Blastomyces spp., y los denominados hongos oportunistas, los cuales suelen ser menos virulentos y requieren de la disminución de la función inmune o la pérdida de la barrera 
epitelial del hospedero para poder causar infección, como es el caso de Candida spp., Aspergillus spp. y Cryptococcus spp. $[37,42]$.

Existen algunos factores de riesgo que propician la invasión, estancia y diseminación de los hongos en el tracto urogenital masculino como son el uso indiscriminado de medicamentos, la insuficiencia renal, la edad (mayores de 40 años), las quemaduras, la diabetes, el cáncer y las alteraciones en el sistema inmune $[33,34,37,40]$. Algunas de estas micosis son la candidiasis, la aspergilosis, la coccidioidomicosis, la criptococosis y

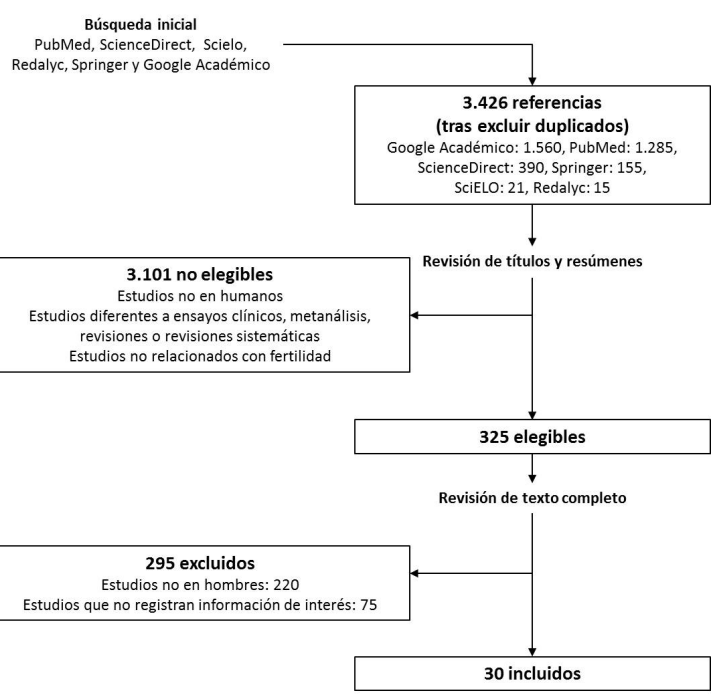

Figura 1. Esquema de la revisión sistemática de los estudios sobre las micosis del tracto urogenital masculino y su relación con la calidad seminal y la fertilidad masculina. la blastomicosis, las cuales se revisarán a continuación.

\section{Candidiasis}

La candidiasis es una infección causada por levaduras del género Candida, comúnmente encontradas en la piel y las mucosas humanas, con una distribución mundial y considerada la única infección micótica de trasmisión sexual $[32,62]$. En las mujeres Candida spp. es responsable de la candidiasis vulvovaginal, mientras que en los hombres produce balanitis, balanopostitis, orquitis y prostatitis $[32,39,45,62]$. El efecto de esta levadura en el semen ha sido poco estudiado y sobre los espermatozoides humanos poco entendido [4,35], aunque se ha demostrado que puede generar cambios en el pH del plasma seminal, además de afectar la morfología, la movilidad, la viabilidad y las funciones mitocondriales de los espermatozoides $[6,44]$.

En el 2006, Golshani y colaboradores [43] reportaron la presencia de Candida spp. en el 2,3\% (3/88) de la muestras seminales evaluadas, y en el 2009, Burrello y colaboradores [44] indicaron el efecto negativo de la presencia de Candida albicans en el semen sobre la movilidad, el potencial de la membrana mitocondrial, la condensación de la cromatina y la apoptosis de los espermatozoides humanos; además, en este mismo estudio se reportó que este efecto negativo dependía del tiempo de interacción. A su vez, en el 2007, Tian y colaboradores [6] reportaron el efecto negativo de Candida albicans y sus factores solubles sobre la movilidad y la morfología espermática en humanos. 


\begin{tabular}{|c|c|c|c|c|c|}
\hline Referencia & $\begin{array}{l}\text { Tipo de } \\
\text { estudio }\end{array}$ & $\begin{array}{l}\text { Lugar } \\
\text { de estudio }\end{array}$ & $\begin{array}{l}\text { Agente } \\
\text { etiológico }\end{array}$ & $\begin{array}{l}\text { Sitio } \\
\text { anatómico } \\
\text { de infección }\end{array}$ & $\begin{array}{l}\text { Situación } \\
\text { clínica }\end{array}$ \\
\hline $\begin{array}{l}\text { Arias y colaboradores } \\
(1999)[42]\end{array}$ & $\begin{array}{l}\text { Capítulo } \\
\text { de libro }\end{array}$ & España & \multirow{13}{*}{ Candida spp. } & \multirow{6}{*}{ Pene } & \multirow{6}{*}{$\begin{array}{l}\text { Balanitis } \\
\text { Balanopostitis }\end{array}$} \\
\hline $\begin{array}{l}\text { Organización Mundial } \\
\text { de la Salud (2005) } \\
\text { [32] }\end{array}$ & Libro & Suiza & & & \\
\hline $\begin{array}{l}\text { De los Santos-Moreno } \\
\text { y colaboradores (2010) } \\
\text { [37] }\end{array}$ & $\begin{array}{l}\text { Artículo } \\
\text { original }\end{array}$ & España & & & \\
\hline $\begin{array}{l}\text { Araiza y colaboradores } \\
\text { (2011) [39] }\end{array}$ & $\begin{array}{l}\text { Artículo de } \\
\text { revisión }\end{array}$ & México & & & \\
\hline $\begin{array}{l}\text { Aridogan y colaborado- } \\
\text { res }(2011)[34]\end{array}$ & $\begin{array}{l}\text { Artículo de } \\
\text { revisión }\end{array}$ & Turquía & & & \\
\hline $\begin{array}{l}\text { Brown y colaboradores } \\
\text { (2012) [38] }\end{array}$ & $\begin{array}{l}\text { Artículo de } \\
\text { revisión }\end{array}$ & Reino unido & & & \\
\hline $\begin{array}{l}\text { Wise y colaboradores } \\
\text { (1999) [35] }\end{array}$ & $\begin{array}{l}\text { Artículo de } \\
\text { revisión }\end{array}$ & Estados Unidos & & \multirow[b]{2}{*}{ Próstata } & \multirow[b]{2}{*}{ Prostatitis } \\
\hline $\begin{array}{l}\text { Golshani y colaborado- } \\
\text { res }(2006)[43]\end{array}$ & $\begin{array}{l}\text { Artículo } \\
\text { original }\end{array}$ & Irán & & & \\
\hline $\begin{array}{l}\text { Burrello y colaborado- } \\
\text { res }(2004)[41]\end{array}$ & $\begin{array}{l}\text { Reporte de } \\
\text { caso }\end{array}$ & Italia & & \multirow{3}{*}{ Semen } & \multirow{3}{*}{$\begin{array}{l}\text { Alteración pH, } \\
\text { viabilidad, } \\
\text { movilidad y } \\
\text { morfología } \\
\text { espermática }\end{array}$} \\
\hline $\begin{array}{l}\text { Tian y colaboradores } \\
\text { (2007) [6] }\end{array}$ & $\begin{array}{l}\text { Artículo } \\
\text { original }\end{array}$ & China & & & \\
\hline $\begin{array}{l}\text { Burrello y colaborado- } \\
\text { res }(2009)[44]\end{array}$ & $\begin{array}{l}\text { Artículo } \\
\text { original }\end{array}$ & Italia & & & \\
\hline $\begin{array}{l}\text { Jenks y colaboradores } \\
(1995)[45]\end{array}$ & $\begin{array}{l}\text { Reporte de } \\
\text { Caso }\end{array}$ & Reino unido & & \multirow[b]{2}{*}{ Epidídimo } & \multirow[b]{2}{*}{ Orquitis } \\
\hline $\begin{array}{l}\text { Wise y colaboradores } \\
(1999)[35]\end{array}$ & $\begin{array}{l}\text { Artículo de } \\
\text { revisión }\end{array}$ & Estados Unidos & & & \\
\hline Negroni R (2012) [46] & $\begin{array}{l}\text { Artículo de } \\
\text { revisión }\end{array}$ & Argentina & \multirow{4}{*}{$\begin{array}{l}\text { Cryptococcus } \\
\text { spp. }\end{array}$} & Pene & $\begin{array}{l}\text { Úlceras, pseu- } \\
\text { dotumores }\end{array}$ \\
\hline $\begin{array}{l}\text { Staib y colaboradores } \\
(1989)[47]\end{array}$ & $\begin{array}{l}\text { Reporte de } \\
\text { caso }\end{array}$ & Alemania & & \multirow[b]{2}{*}{ Próstata } & \multirow[b]{2}{*}{ Prostatitis } \\
\hline $\begin{array}{l}\text { Kiertiburanakul y cola- } \\
\text { boradores (2004) [48] }\end{array}$ & $\begin{array}{l}\text { Reporte de } \\
\text { caso }\end{array}$ & Tailandia & & & \\
\hline $\begin{array}{l}\text { Staib y colaboradores } \\
(1989)[47]\end{array}$ & $\begin{array}{l}\text { Reporte de } \\
\text { caso }\end{array}$ & Alemania & & Semen & $\begin{array}{l}\text { Alteración } \\
\text { volumen y } \\
\text { morfología } \\
\text { espermática }\end{array}$ \\
\hline $\begin{array}{l}\text { Sohail y colaboradores } \\
\text { (1978) [49] }\end{array}$ & $\begin{array}{l}\text { Artículo de } \\
\text { revisión }\end{array}$ & Estados Unidos & \multirow{3}{*}{$\begin{array}{l}\text { Coccidioides } \\
\text { spp. }\end{array}$} & Próstata & Prostatitis \\
\hline $\begin{array}{l}\text { Weyrauch y colabora- } \\
\text { dores }(1950)[50]\end{array}$ & $\begin{array}{l}\text { Reporte de } \\
\text { caso }\end{array}$ & Estados Unidos & & Semen & $\begin{array}{l}\text { Alteración } \\
\text { transporte }\end{array}$ \\
\hline $\begin{array}{l}\text { Klett y Hong (2003) } \\
{[51]}\end{array}$ & $\begin{array}{l}\text { Reporte de } \\
\text { caso }\end{array}$ & Estados Unidos & & Epidídimo & Orquitis \\
\hline
\end{tabular}




\begin{tabular}{|c|c|c|c|c|c|}
\hline $\begin{array}{l}\text { Wise y colaboradores } \\
\text { (2002) [33] }\end{array}$ & $\begin{array}{l}\text { Capítulo } \\
\text { libro }\end{array}$ & Estados Unidos & \multirow{5}{*}{ Aspergillus spp. } & Uretra & $\begin{array}{l}\text { Uretritis, } \\
\text { obstrucciones, } \\
\text { disuria }\end{array}$ \\
\hline $\begin{array}{l}\text { Hope y colaboradores } \\
(2005) \text { [52] }\end{array}$ & $\begin{array}{l}\text { Artículo de } \\
\text { revisión }\end{array}$ & Estados Unidos & & Semen & Transporte \\
\hline $\begin{array}{l}\text { Abbas y colaboradores } \\
(1995)[53]\end{array}$ & $\begin{array}{l}\text { Reporte de } \\
\text { caso }\end{array}$ & Paquistán & & \multirow{3}{*}{ Próstata } & \multirow{3}{*}{ Prostatitis } \\
\hline $\begin{array}{l}\text { Patterson y colabora- } \\
\text { dores }(2000) \text { [54] }\end{array}$ & $\begin{array}{l}\text { Artículo } \\
\text { original }\end{array}$ & Estados Unidos & & & \\
\hline $\begin{array}{l}\text { Hope y colaboradores } \\
\text { (2005) [52] }\end{array}$ & $\begin{array}{l}\text { Artículo de } \\
\text { revisión }\end{array}$ & Estados Unidos & & & \\
\hline $\begin{array}{l}\text { Rosenberg y colabora- } \\
\text { dores (1994) [55] }\end{array}$ & $\begin{array}{l}\text { Artículo de } \\
\text { revisión }\end{array}$ & Estados Unidos & \multirow{5}{*}{ Malassezia spp. } & \multirow{4}{*}{ Pene } & \multirow{4}{*}{$\begin{array}{l}\text { Psoriasis, ba- } \\
\text { lanopostitis }\end{array}$} \\
\hline $\begin{array}{l}\text { López-Martinez y cola- } \\
\text { boradores (2005) [36] }\end{array}$ & $\begin{array}{l}\text { Artículo de } \\
\text { revisión }\end{array}$ & México & & & \\
\hline $\begin{array}{l}\text { Aridoğan y colaborado- } \\
\text { res (2005) [56] }\end{array}$ & $\begin{array}{l}\text { Artículo } \\
\text { original }\end{array}$ & Turquía & & & \\
\hline $\begin{array}{l}\text { Alsterholm y colabora- } \\
\text { dores (2008) [57] }\end{array}$ & $\begin{array}{l}\text { Reporte de } \\
\text { investiga- } \\
\text { ción }\end{array}$ & Suecia & & & \\
\hline $\begin{array}{l}\text { Thayikkannu y colabo- } \\
\text { radores (2015) [58] }\end{array}$ & $\begin{array}{l}\text { Artículo de } \\
\text { revisión }\end{array}$ & India & & Semen & Transporte \\
\hline $\begin{array}{l}\text { Seo y colaboradores } \\
\text { (1997) [59] }\end{array}$ & $\begin{array}{l}\text { Reporte de } \\
\text { caso }\end{array}$ & Estados Unidos & \multirow{3}{*}{$\begin{array}{l}\text { Blastomyces } \\
\text { spp. }\end{array}$} & Semen & Transporte \\
\hline $\begin{array}{l}\text { Witorsch y colaborado- } \\
\text { res (1968) [60] }\end{array}$ & $\begin{array}{l}\text { Artículo } \\
\text { original }\end{array}$ & Estados Unidos & & Epidídimo & Orquitis \\
\hline $\begin{array}{l}\text { García-Morúa y cola- } \\
\text { boradores (2010) [61] }\end{array}$ & $\begin{array}{l}\text { Artículo de } \\
\text { revisión }\end{array}$ & México & & Próstata & Prostatitis \\
\hline
\end{tabular}

\section{Criptococosis}

Cryptococcus spp., agente causal de la criptococosis, son levaduras encapsuladas reconocidas como uno de los hongos oportunistas más comunes y asintomáticos. Las especies más reportadas son Cryptococcus neoformans y Cryptococcus gattii, las cuales están presentes en la piel e infectan los tractos respiratorio y urogenital [48], lo que puede generar prostatitis, abscesos renales, úlceras y pseudotumores en el pene [46].

En los individuos con prostatitis causada por Cryptococcus spp. es posible, generalmente, aislar el microorganismo de los cultivos de orina obtenidos después de realizar un masaje prostático [35]. Sin embargo, en 1989, Staib y colaboradores [47] reportaron que, luego de 65 días de cultivo de muestras de orina, no se obtenía ningún rastro de Cryptococcus neoformans, aunque lograron detectarlo en cultivos de semen ( $\left.3 \times 10^{5} \mathrm{UFC} / \mathrm{mL}\right)$; además, indicaron que el volumen seminal había disminuido y que los espermatozoides presentaban alterada su morfología. 


\section{Coccidioidomicosis}

Coccidioides spp. es un género de hongos dimórficos, agentes causales de la coccidioidomicosis y endémicos en el sur de los Estados Unidos, Centro y Suramérica. Las especies más reportadas son Coccidiodes immitis y Coccidiodes posadasii, las cuales producen infecciones asintomáticas en el $60 \%$ de los casos [35]. La difusión se produce por vía hematógena y los sitios de infección más comunes incluyen la piel, los huesos, las articulaciones, las meninges y el tejido blando, aunque existen reportes de identificación de estos hongos prácticamente en cualquier órgano $[35,49]$.

En el 2005, Sohail y colaboradores [49] reportaron 24 casos de coccidioidomicosis en el tracto urogenital masculino, la mayoría de estos causados por diseminación sistémica y con identificación por medio de biopsias. De manera similar, en 2003, Klett y Hong [51] reportaron un caso de coccidioidomicosis pulmonar primaria en un hombre de 44 años, la cual se difundió a los testículos y al epidídimo.

A través de estudios post mortem se ha encontrado que el tracto genitourinario es un lugar de común diseminación de Coccidioides spp. [51], donde los riñones son afectados en un $40 \%$ de los casos, mientras que la próstata y el escroto en un $6 \%$ y $1,5 \%$, respectivamente [35]. Además, en 1950, Weyrauch y colaboradores [50] encontraron que este microorganismo puede ser transportado en el líquido seminal.

\section{Aspergilosis}

La aspergilosis es causada por las especies del género Aspergillus, hongos filamentosos que usualmente se encuentran en los suelos y en la materia en descomposición. Las especies más reportadas como posibles agentes infecciosos son Aspergillus niger, Aspergillus oryzae, Aspergillus zydowii, Aspergillus fumigatus y Aspergillus flavus. Estos hongos son conocidos por ser un patógeno primario en plantas y oportunista en los humanos [53], incluso se considera que la aspergilosis es la principal causa de morbilidad y mortalidad en personas inmunosuprimidas [54]. El 80\% de las infecciones causadas por Aspergillus spp. se dan en el sistema respiratorio, oídos y cerebro, causando alergias, sinusitis, otitis, bronquitis y úlceras [35,54]. En el tracto genitourinario es inusual encontrar a Aspergillus spp., aunque se ha evidenciado su presencia mediante cultivos de muestras de orina, en biopsias y mediante reacción en cadena de la polimerasa [33] en riñón, uretra y próstata, sitios donde generan fallas renales, disuria y obstrucciones [52].

\section{Infecciones por Malassezia spp.}

Malassezia spp., antes conocido como Pityrosporum spp., es un género de hongos dimórficos y lipofílicos que habitan en el humano comúnmente en la cara, la 
parte alta de la espalda y el cuero cabelludo, y pueden llegar a colonizar el pene, donde provocan psoriasis, pitiriasis y balanopostitis $[36,55,58]$. Malassezia furfur, Malassezia globosa, Malassezia sympodialis y Malassezia obtusa son las especies más reportadas como causales de infección [56]. Alsterholm y colaboradores (2008) [57] reportaron la presencia de Malassezia spp. en 23 de 100 hombres con diagnóstico de balanopostitis.

\section{Blastomicosis}

Blastomyces spp. es un género de hongos dimórficos, endémicos de los Estados Unidos, comúnmente encontrados en los suelos. La especie más reportada como patógena es Blastomyces dermatitidis y la infección más común es la pulmonar, ya que normalmente se adquiere por la inhalación de esporas, aunque se ha evidenciado su presencia en la próstata y el epidídimo [60,61]. En 1997 Seo y colaboradores [59] reportaron un caso de prostatitis y epididimitis en un hombre de 36 años, el cual presentó hematospermia, disuria, fiebre, escalofríos y dolor pélvico. Inicialmente, al realizar los cultivos de orina del paciente, no se evidenció el microorganismo; sin embargo, al realizar una biopsia prostática, una epididectomia parcial y cultivos de semen se encontró la presencia de Blastomyces dermatitidis.

\section{Discusión}

Las infecciones micóticas del tracto urogenital masculino podrían ser consideradas como una amenaza para la fertilidad. A pesar de que el incremento en el número de personas inmunosuprimidas ha disparado una alerta en el control y la prevención de las infecciones micóticas, su transmisión y diseminación es cada vez más común $[35,45]$; además, la mayoría de los casos son asintomáticos, lo que genera que los portadores continúen transmitiéndolos sin saberlo.

Los hongos implicados en estas infecciones deberían ser incluidos entre los agentes etiológicos de fallas en la fecundación debido a que afectan la función normal de los órganos sexuales, contaminan el semen, se adhieren a los espermatozoides, inhiben su movilidad y afectan su morfología [33,35,38,44,46,51].

Además, es importante recalcar que aunque se emplean técnicas de selección espermática, como el swim-up y los gradientes de selección, no se logra separar a los espermatozoides de los hongos, lo que dificulta el uso de estas metodologías en los procedimientos de reproducción asistida, como la fecundación in vitro y la inyección intracitoplasmática de espermatozoides [41].

Finalmente, debido a que existen pocas investigaciones y control sobre las infecciones por hongos es necesario realizar más trabajos que permitan aumentar 
el conocimiento total del daño de estos microorganismos y sus factores solubles sobre la fertilidad masculina.

\section{Conclusiones}

El tracto genitourinario es un sitio potencial para la infección por hongos de forma primaria, invasiva o diseminada, lo que afecta el potencial fértil. Si estas infecciones se detectaran y trataran de forma pronta y correcta se evitaría el aumento de la diseminación, la morbilidad y la mortalidad por causa de estos microrganismos.

\section{Bibliografía}

1. Brugo-Olmedo S, Chillik C, Kopelman S. Definición y causas de la infertilidad. Rev Colomb Obstet Ginecol 2003; 54: 227-248.

2. Palma C, Vinay JI. Infertilidad masculina. Rev Med Clin Condes 2014; 25: 122-128.

3. Huidobro C. Infertilidad masculina. Rev Med Clin Condes 2010; 21: 368-375.

4. Gimenes F, Souza RP, Bento JC, Teixeira JJ, Maria-Engler SS, Bonini MG, et al. Male infertility: a public health issue caused by sexually transmitted pathogens. Nat Rev Urol 2014; 11: 672-687.

5. Zegers-Hochschild F, Adamson GD, Mouzon Jd, Ishihara O, Mansour R, Nygren K, et al. Glosario de terminología en Técnicas de Reproducción Asistida (TRA). Versión revisada y preparada por el International Committee for Monitoring Assisted Reproductive Technology (ICMART) y la Organización Mundial de la Salud (OMS). 2010: 1-10.

6. Tian $\mathbf{Y H}$, Xiong JW, Hu L, Huang DH, Xiong CL. Candida albicans and filtrates interfere with human spermatozoal motility and alter the ultrastructure of spermatozoa: an in vitro study. Int J Androl 2007; 30: 421-429.

7. Tournaye H, Krausz C, Oates RD. Novel concepts in the aetiology of male reproductive impairment. Lancet Diabetes Endocrinol 2016.

8. Zea-Mazo JW, Negrette-Mejia YA, Cardona-Maya W. [Virus of sexual transmission: semen and virus relationship]. Actas Urol Esp 2010; 34: 845-853.

9. World Health Organization. WHO laboratory manual for the examination and processing of human semen (ed 5a). Ginebra, Suiza: WHO Press; 2010.

10. Munuce MJ, Cardona-Maya W, Berta CL. [Is there an association between sperm nor- mal morphology and their kinetic displacement?]. Actas Urol Esp 2006; 30: 591-597.

11. Cardona Maya WD, Olivera Angel M, Cadavid AP. [Evaluation of the calcium ionophore induced acrosome reaction: a more realistic approach to the fecundant capacity of the spermatozoid]. Arch Esp Urol 2006; 59: 501-510.

12. de los Rios J, Cardona WD, Berdugo JA, Correa C, Arenas A, Olivera-Angel $M$, et al. [Sperm parameters in 113 subjects after recent fatherhood did not correlate with WHO standards]. Arch Esp Urol 2004; 57: 147152.

13. Cardona-Maya WD, Cadavid AP. [Evaluation of the role of the monosaccharides, mannose and $\mathrm{N}$-acetylglucosamine in the induction of the acrosome reaction in human spermatozoa]. Actas Urol Esp 2005; 29: 676684.

14. Cardona Maya WD, Berdugo Gutierrez JA, de los Rios J, Cadavid Jaramillo AP. Functional evaluation of sperm in Colombian fertile men. Arch Esp Urol 2007; 60: 827831.

15. Mayorga-Torres BJ, Camargo M, Cadavid AP, du Plessis SS, Cardona Maya WD. Are oxidative stress markers associated with unexplained male infertility? Andrologia 2016.

16. Mayorga-Torres BJ, Camargo M, Agarwal A, du Plessis SS, Cadavid AP, Cardona Maya WD. Influence of ejaculation frequency on seminal parameters. Reprod Biol Endocrinol 2015; 13: 47.

17. Puerta-Suárez J, Villegas-Castaño A, Serna-Quintana GJ, Martínez A, RomeroPalacio J, Giraldo M, et al. Espermocultivo: crecimiento bacteriano del eyaculado y su relación con los parámetros seminales. Rev Chil Obstet Ginecol 2015; 80: 33-40. 
18. Puerta-Suárez J, Giraldo M, Cadavid ÁP, Cardona-Maya W. Infecciones bacterianas del tracto reproductivo masculino y su papel en la fertilidad. Rev Chil Obstet Ginecol 2014; 79: 209-217.

19. Puerta-Suárez J, Cardona-Maya WD. Prevalencia de Chlamydia trachomatis, Neisseria gonorrhoeae y Ureaplasma urealyticum en muestras de semen: efectos sobre la calidad espermática. Urol Colomb 2016; 25: 219224.

20. Cano-Cháves A, Galarzo-Pardo S, PuertaSuárez J, Giraldo M, Cadavid ÁP, Cardona-Maya WD. Efecto de las bacterias uropatógenas y de los factores solubles de su metabolismo sobre la calidad espermática: Escherichia coli y Enterococcus faecalis. Clin Invest Gin Obst 2016; Ene 12 [Epub ahead of print].

21. Galarzo-Pardo S, Cano-Cháves MA, Puerta-Suarez J, Giraldo M, Mayorga BJM, Cadavid ÁP, et al. Efecto de los factores solubles de Staphylococcus aureus, Staphylococcus capitis y Staphylococcus epidermidis sobre la funcionalidad espermática. Rev Chil Obstet Ginecol 2015; 80: 316-323.

22. Organización Mundial de la Salud. Infecciones de transmisión sexual. Nota descriptiva No110. 2016. Disponible: http://www.who. int/mediacentre/factsheets/fs110/es/. Consultado: ene 2017.

23. Cardona-Maya W, Velilla PA, Montoya CJ, Cadavid A, Rugeles MT. In vitro human immunodeficiency virus and sperm cell interaction mediated by the mannose receptor. J Reprod Immunol 2011; 92: 1-7.

24. Cardona-Maya W, Rugeles MT, Cadavid ÁP. Interaction between human sperm and human immunodeficiency virus. Actas Urol Esp 2009; 33: 223-226.

25. Cardona-Maya W, Lopez-Herrera A, Velilla-Hernandez P, Rugeles MT, Cadavid AP. The role of mannose receptor on HIV-1 entry into human spermatozoa. Am J Reprod Immunol 2006; 55: 241-245.

26. Cardona-Maya W, Velilla P, Montoya CJ, Cadavid A, Rugeles MT. Presence of HIV-1 DNA in spermatozoa from HIV-positive patients: changes in the semen parameters. Curr HIV Res 2009; 7: 418-424.

27. Ceballos A, Remes Lenicov F, Sabatte J, Rodriguez Rodrigues C, Cabrini M, Jancic C, et al. Spermatozoa capture HIV-1 through heparan sulfate and efficiently transmit the virus to dendritic cells. J Exp Med 2009; 206: 2717-2733.

28. Salvatori F, De Martino M, Galli L, Vierucci A, Chieco-Bianchi L, De Rossi A. Horizontal transmission of human immunodefi- ciency virus type 1 from father to child. AIDS Res Hum Retroviruses 1998; 14: 1679-1685.

29. Ceballos A, Andreani G, Ayala SE, Romer Y, Rimoldi I, Agosti MR, et al. Epidemiological and molecular evidence of two events of father-to-child HIV type 1 horizontal transmission. AIDS Res Hum Retroviruses 2004; 20: 789-793.

30. Cardona-Maya WD, Hernandez PA, Henao DE. Male Ebola Survivors: Do Not Forget to Use a Condom! Reprod Sci 2014.

31. Cardona Maya WD, Du Plessis SS, Velilla PA. Semen as virus reservoir? J Assist Reprod Genet 2016; 33: 1255-1256.

32. Organización Mundial de la Salud. Guías para el tratamiento de las infecciones de transmisión sexual. Ginebra, Suiza: Ediciones de la OMS; 2005.

33. Wise GJ. Fungal and actinomycotic infections of the genitourinary system. En: Walsh $P C$, Retik $A B$, Vaughn-Jr ED, Wein AJ, eds. Campbell's Urology (ed 8a). Filadelfia, Estados Unidos: W.B. Saunders; 2002: 803-804.

34. Aridogan IA, Izol V, Ilkit M. Superficial fungal infections of the male genitalia: a review. Crit Rev Microbiol 2011; 37: 237-244.

35. Wise GJ, Talluri GS, Marella VK. Fungal infections of the genitourinary system: manifestations, diagnosis, and treatment. Urol Clin North Am 1999; 26: 701-718, vii.

36. López-Martínez R. Ecología de los hongos patógenos para el hombre. Rev Mex Mic 2005; 21: 85-92.

37. de los Santos Moreno A, Gómez NC, Japón F, Iglesias MR. Infecciones por hongos. Med - Programa Form Médica Contin Acreditado 2010; 10: 3558-3568.

38. Brown GD, Denning DW, Gow NA, Levitz SM, Netea MG, White TC. Hidden killers: human fungal infections. Sci Transl Med 2012; 4: 165rv113.

39. Araiza J, Montes OG, Ponce ORM, Bonifaz A. Balanitis y balanopostitis candidósica. Comunicación de 20 casos. Dermatología Rev Mex 2011; 55: 342-346.

40. Weidner W, Pilatz A, Diemer T, Schuppe HC, Rusz A, Wagenlehner F. Male urogenital infections: impact of infection and inflammation on ejaculate parameters. World J Urol 2013; 31: 717-723.

41. Burrello N, Calogero AE, Perdichizzi A, Salmeri M, D'Agata R, Vicari E. Inhibition of oocyte fertilization by assisted reproductive techniques and increased sperm DNA fragmentation in the presence of Candida albicans: a case report. Reprod Biomed Online 2004; 8: 569-573. 
42. Arias J, Aller MÁ, Arias JI, Lorente L. Fisiopatología quirúrgica: Traumatismos, Infecciones, Tumores. Madrid, España: Editorial Tébar; 1999.

43. Golshani M, Taheri S, Eslami G, Rahbar AS, Fallah F, Goudarzi H. Genital Tract Infection in Asymptomatic Infertile Men and Its Effect on Semen Quality. Iran J Public Health 2006; 35: 81-84.

44. Burrello N, Salmeri M, Perdichizzi A, Bellanca S, Pettinato G, D'Agata R, et al. Candida albicans experimental infection: effects on human sperm motility, mitochondrial membrane potential and apoptosis. Reprod Biomed Online 2009; 18: 496-501.

45. Jenks P, Brown J, Warnock D, Barnes N. Candida glabrata epididymo-orchitis: an unusual infection rapidly cured with surgical and antifungal treatment. J Infect 1995; 31: 7172.

46. Negroni R. Cryptococcosis. Clin Dermatol 2012; 30: 599-609.

47. Staib F, Seibold M, L'Age M, Heise W, Skorde J, Grosse G, et al. Cryptococcus neoformans in the seminal fluid of an AIDS patient. A contribution to the clinical course of cryptococcosis. Mycoses 1989; 32: 171-180.

48. Kiertiburanakul $\mathbf{S}$, Sungkanuparph $\mathbf{S}$, Buabut B, Pracharktam R. Cryptococcuria as a manifestation of disseminated cryptococcosis and isolated urinary tract infection. Jpn J Infect Dis 2004; 57: 203-205.

49. Sohail MR, Andrews PE, Blair JE. Coccidioidomycosis of the male genital tract. J Urol 2005; 173: 1978-1982.

50. Weyrauch HM, Norman FW, Bassett JB. Coccidioidomycosis of the genital tract. Calif Med 1950; 72: 465-468.

51. Klett D, Hong Y. Coccidioidomycosis of the Testis and Epididymis. Open J Urol 2013; 3: 87-89.

52. Hope WW, Walsh TJ, Denning DW. The invasive and saprophytic syndromes due to Aspergillus spp. Med Mycol 2005; 43 Suppl 1: S207-238.

53. Abbas F, Kamal MK, Talati J. Prostatic aspergillosis. J Urol 1995; 153: 748-750.

54. Patterson TF, Kirkpatrick WR, White $M$, Hiemenz JW, Wingard JR, Dupont $B$, et al. Invasive aspergillosis. Disease spectrum, treatment practices, and outcomes. I3 Aspergillus Study Group. Medicine (Baltimore) 2000; 79: 250-260.

55. Rosenberg EW, Noah PW, Skinner RB, Jr. Microorganisms and psoriasis. J Natl Med Assoc 1994; 86: 305-310.

56. Aridogan IA, Ilkit M, Izol V, Ates A. Malassezia and Candida colonisation on glans penis of circumcised men. Mycoses 2005; 48: 352356.

57. Alsterholm M, Flytstrom I, Leifsdottir R, Faergemann J, Bergbrant IM. Frequency of bacteria, Candida and malassezia species in balanoposthitis. Acta Derm Venereol 2008; 88: 331-336.

58. Thayikkannu AB, Kindo AJ, Veeraraghavan M. Malassezia-Can it be Ignored? Indian J Dermatol 2015; 60: 332-339.

59. Seo R, Oyasu R, Schaeffer A. Blastomycosis of the epididymis and prostate. Urology 1997; 50: 980-982.

60. Witorsch P, Utz JP. North American blastomycosis: a study of 40 patients. Medicine (Baltimore) 1968; 47: 169-200.

61. García-Morúa A, Gutiérrez-García JD, Valdes-Sepúlveda F, Lozano-Salinas JF, Gómez-Guerra LS. Blastomicosis prostática: presentación de un caso y revisión de la literatura. Actas Urol Esp 2010; 34: 212-213.

62. Duque C, Gómez B, Uribe O, Alarcón J, Soto F, Uran L, et al. Caracterización de la candidiasis vulvovaginal en mujeres de la ciudad de Medellín, Colombia. Nova 2009; 7: 157-160. 